This item was submitted to Loughborough's Research Repository by the author.

Items in Figshare are protected by copyright, with all rights reserved, unless otherwise indicated.

\title{
Interoperable manufacturing knowledge systems
}

PLEASE CITE THE PUBLISHED VERSION

https://doi.org/10.1080/00207543.2017.1391416

PUBLISHER

(C) Taylor \& Francis

VERSION

AM (Accepted Manuscript)

PUBLISHER STATEMENT

This work is made available according to the conditions of the Creative Commons Attribution-NonCommercialNoDerivatives 4.0 International (CC BY-NC-ND 4.0) licence. Full details of this licence are available at: https://creativecommons.org/licenses/by-nc-nd/4.0/

\section{LICENCE}

CC BY-NC-ND 4.0

\section{REPOSITORY RECORD}

Palmer, Claire, Zahid Usman, Osiris Canciglieri, Andreia Malucelli, and Robert I.M. Young. 2019.

“Interoperable Manufacturing Knowledge Systems”. figshare. https://hdl.handle.net/2134/26767. 

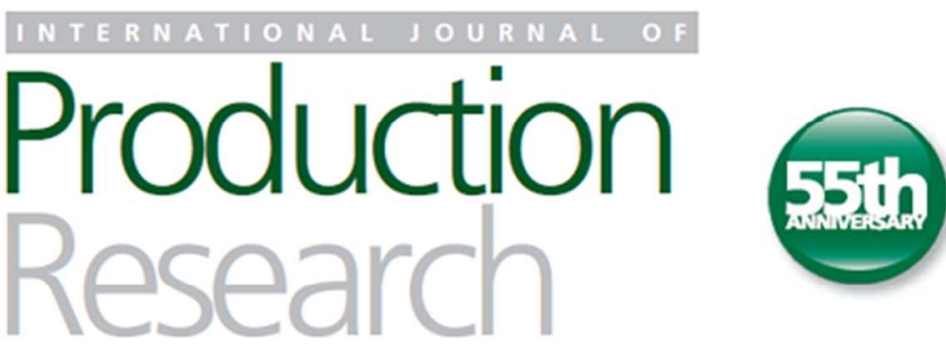

Official Joumal of the Intemational Foundation for Production Research

Editor-in-Chief: Alexandre Dolgui

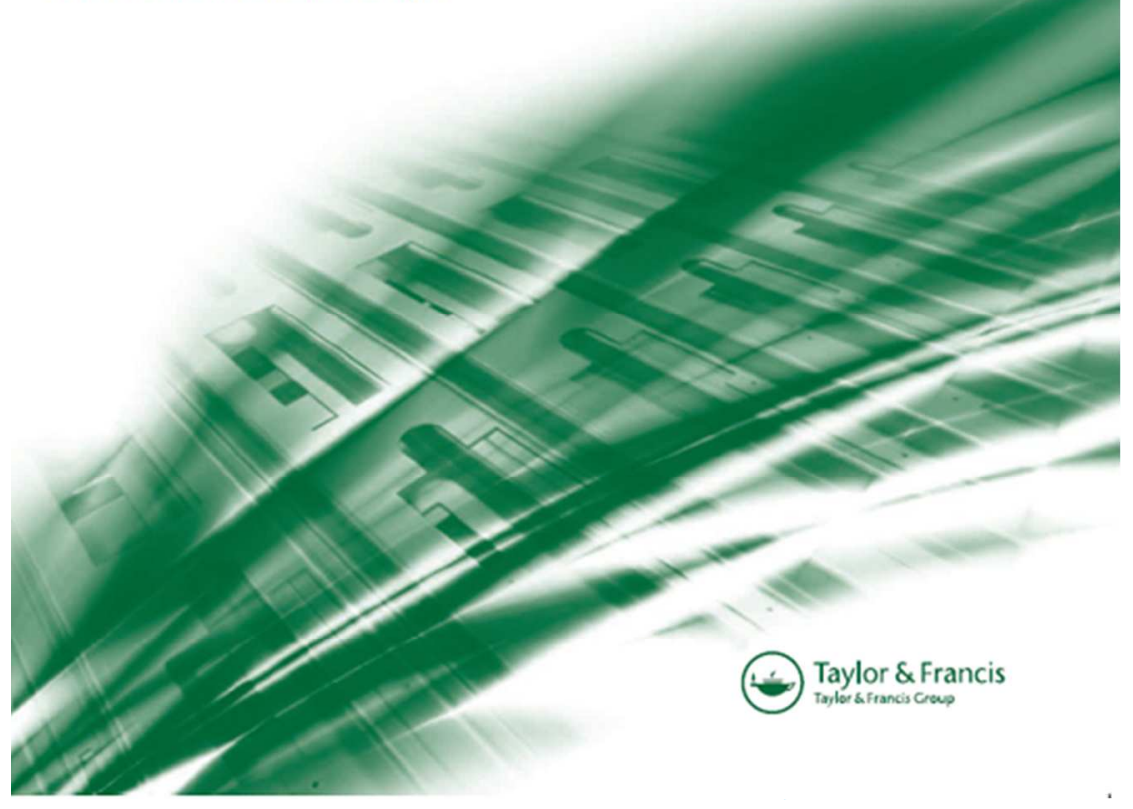

Interoperable manufacturing knowledge systems

\begin{tabular}{|r|l|}
\hline Journal: & International Journal of Production Research \\
\hline Manuscript ID & TPRS-2017-IJPR-0267.R1 \\
\hline Manuscript Type: & Special Issue Paper \\
\hline Complete List of Authors: & $\begin{array}{l}\text { Palmer, Claire; Loughborough University, Wolfson School of Mech, Elect } \\
\text { and Man Engineering } \\
\text { Usman, Zahid; University of Coventry, UK, Faculty of Engineering, }\end{array}$ \\
\hline
\end{tabular}


2

\begin{tabular}{|c|l|}
\hline & $\begin{array}{l}\text { Environment and Computing } \\
\text { Canciglieri Junior, Osiris; Pontifical Catholic University of Paraná } \\
\text { Malucelli, Andreia; Pontifical Catholic University of Paraná } \\
\text { Young, Robert; Loughborough University, Wolfson School of Mech, Elect } \\
\text { and Man Engineering }\end{array}$ \\
\hline Keywords: & $\begin{array}{l}\text { INTEROPERABILITY, INTELLIGENT MANUFACTURING SYSTEMS, } \\
\text { KNOWLEDGE ENGINEERING, MANUFACTURING INFORMATION SYSTEMS, } \\
\text { ONTOLOGIES }\end{array}$ \\
\hline Keywords (user): $:$ & $\begin{array}{l}\text { decision support, reference ontologies, manufacturing systems, knowledge } \\
\text { sharing }\end{array}$ \\
\hline \multicolumn{2}{|l}{} \\
\hline
\end{tabular}

\section{SCHOLARONE ${ }^{\text {IN }}$}

Manuscripts 


\section{Interoperable manufacturing knowledge systems}

Claire Palmer ${ }^{\mathrm{a}}$, Zahid Usman $^{\mathrm{b}}$, Osiris Canciglieri Junior ${ }^{\mathrm{c}}$, Andreia Malucelli ${ }^{\mathrm{c}}$, Robert I.M.Young ${ }^{\mathrm{a}}$.

a Loughborough University, Loughborough, Leicestershire, UK

${ }^{b}$ Coventry University, Coventry, $U K$

${ }^{c}$ Pontifical Catholic University of Paraná, Curitiba, Brazil

Corresponding author:

Prof R I M Young, (‥i.young@1boro.ac.uk), Wolfson school of mechanical, electrical and manufacturing engineering, Loughborough University, Loughborough, LE11 3TU, UK. 


\title{
Interoperable manufacturing knowledge systems
}

\begin{abstract}
For many years now, the importance of semantic technologies, that provide a formal, logic based route to sharing meaning, has been recognized as offering the potential to support interoperability across multiple related applications and hence drive manufacturing competitiveness in the digital manufacturing age. However, progress in support of manufacturing enterprise interoperability has tended to be limited to fairly narrow domains of applicability. This paper presents a progression of research and understanding, culminating in the work undertaken in the recent EU FLEXINET project, to develop a comprehensive manufacturing reference ontology that can (a) support the clarification of understanding across domains, (b) support the ability to flexibly share information across interacting software systems and (c) provide the ability to readily configure company knowledge bases to support interoperable manufacturing systems.
\end{abstract}

KEYWORDS: interoperability, decision support, reference ontologies, manufacturing systems, knowledge sharing.

\section{Introduction}

Competitive manufacturing industry must be able to react to change and to understand the balance of possible options when making decisions on complex multi-faceted problems. To be able to make high quality, timely decisions across a range of complex factors that impact manufacturing decision making requires high quality information and knowledge to be available at the time key decisions are made. However each business domain requires its own specific discipline's view of the necessary information that it needs. While current software solutions are very good a providing local domain support they do not provide the well-integrated, trans-disciplinary and holistic approaches that are critical to long-term competitive solutions (Huber 2014).

The effective exploitation of semantic technologies has the potential to solve a critical part of this problem through the provision of a formal logic based route to sharing meaning across multiple domains (Borgo et al. 2007, Chungoora et al, 2012). These, through the application of formal logic, have the potential to provide substantially more comprehensive solutions than the industrial data standard approaches that have been employed to date (Chungoora et al, 2013).

The paper begins by providing the background to the problem and argues progressively for the need for a manufacturing reference ontology, the methods needed to construct and use such an ontology and the future work that is still needed to fully exploit the approach to provide significant industrial benefit.

\section{Background to the problem}

\subsection{A business perspective}

While there are many different manufacturing sectors they all have the same sorts of problems with information, most especially with access to information and the sharing of information. Information to support decisions in manufacturing comes from many different sources and is needed to support many different types of decisions. Each group within a manufacturing business, such as in design, production, maintenance, procurement and sustainability, will have it's own types of information. Different factories, customers, suppliers and systems will work with different information and 
different global constraints will have importance dependent on global supplier and market locations.

Each business area of activity needs multiple sources of knowledge to best support decisions, with the efforts towards improving concurrency in product design being a very good example that highlights the need for not only design functional knowledge but also design for manufacture and assembly, design for operation, design for sustainability and even business and market knowledge.

A critical business requirement is to ensure that any potential problems in the ability of new systems to interoperate within complex, flexible, scalable and reconfigurable software environments can be clearly identified in order to ensure interoperable solutions. This is essential in minimising the substantial cost and time loss implications of introducing new systems that are incompatible with the holistic requirements of the business. A clear understanding of the implications of change is of major importance when operating in a dynamic environment with on-going cost, time and quality pressures in globally competitive markets. Providing solutions to meet this need are very much in line with the present day drive towards Industrie 4.0, Smart Manufacturing and the exploitation of cyber-physical systems (Kagermann et al, 2013).

\subsection{An ICT perspective}

Manufacturing industry employs an extensive range of software tools to support their business activities. A simple illustration of a some of the main tools are also shown in figure 1: with Product Lifecycle Management (PLM), Enterprise Resource Planning (ERP), Supply Chain Management (SCM), Manufacturing Execution Systems (MES) Supervisory Control and Data Acquisition (SCADA) along with specific machine control systems providing perhaps the most significant coverage from high level design and tactical planning activities through to shop floor machine control and monitoring. Figure 1 also indicates the complexity of the problem of sharing information and knowledge in a meaningful way. For example the arrows related to the computational systems indicate an ideal situation where information can be communicated in all directions. This is not the case in reality.

These manufacturing software support tools each provide valuable information support to decision makers but they are not well integrated and traditional methods of integration, via interfacing, are expensive and error prone (Ray \& Jones, 2006). The use of industrial data standards can be helpful, but currently these tend to be focused on narrow domains and are not well suited to the breadth of information sharing that needs to be managed across manufacturing (Chungoora et al, 2013). Perhaps ISA-95 (IEC/ISO 62264) provides the most useful reference standard towards the interoperation of manufacturing operations tools, but that too is limited by the lack of semantic consistence in interpretation. For example (Hastilow, 2013) illustrates the problem of misalignment of interpretation between users of ISA-95, identifying 83 errors in a real world example and demonstrating how these could have been avoided if formal semantic approaches had been used. The need for improved standardisation approaches in industrial data standards has been recognised through the work of ISO TC184 SC4 on "Industrial Data Integrated Ontologies and Models (IDIOM)" (Leal \& Feeney, 2010) and also in the standardisation task force report of the EU FInES cluster (Pattenden, Young \& Zelm, 2012).

Finding a robust and consistently interpretable way of representing information such that it can be reliably shared is a substantial problem. Formal logic based methods 


\subsection{An ontological perspective}

Ontologies are used in the computing world for the purposes of communication, computational inferences, information \& knowledge organization, exchange and reuse (Gruninger and Lee 2002). An ontology, as a common basis for shared meaning, can be used for the purpose of knowledge sharing and interoperability across multiple domains. Ontologies in concurrent engineering can support interoperability between systems and support product design and software development (Roche, 2000). Ontologies can play a pivotal role in knowledge management by providing a better way of representing knowledge and supporting the development of reusable and shareable knowledge bases (Sureephong 2008).

Initial approaches to semantic interoperability have been achieved through ontology matching approaches (Shvaiko and Euzenat, 2013; Zdravković et al, 2011; Ye et al, 2008), interchange formats (Ushold et al, 1998; Chen et al, 2009) and reference ontologies (Annamalai et al, 2011; Foufou et al, 2005; Borsato, M., 2014; Chungoora and Young, 2011). These works start to show the potential benefits that can be gained from the use of formal logic but none of them meet the complex knowledge sharing requirements of manufacturing businesses, where all the key aspects of the business must interact and be able to share information, covering business model development and maintenance, new product and process development, production planning and operation, and on through to product operation, service and end-of-life management. 
The aim of manufacturing reference ontologies is to provide an underpinning formal semantic structure that can meet the above need,supporting the development of flexible systems that can share manufacturing knowledge across the multiple manufacturing related domains. This approach, described in the next sub-section, effectively sit between domain ontologies, which are very specific and foundation ontologies such as DOLCE, SUMO, BFO (Mascardi et al., 2010) which are very generic. For example BFO provides formal semantic definitions for terms such as Continuants such as Material and Information entities and Occurrents such as Processes. $\mathrm{BFO}$, as other foundation ontologies, leaves the user to specialise these terms into more specific meaningful terms for their own use. In the case of manufacturing the aim in our work is to exploit this approach to provide the core semantics for manufacturing that enables cross-disciplinary sharing of knowledge. i.e. to provide the core semantics for manufacturing that can then be referenced and further specialised to support the multicontext domains needed in a manufacturing organisation. The idea of a reference ontology fits with the integration model concepts of the "IIDEAS" architecture, with foundation concepts that are used to build general concepts that are then used to build specific concepts (West and Fowler, 2001), but with the important addition of the use of formal logic.

A broad range of research has contributed to manufacturing ontology understanding with a useful review provided in (Usman et al., 2013). Since then further examples can be seen in (Borsato, 2014) related to sustainable manufacturing, (Bruno et al., 2016) related to Product Lifecycle Management, and (Palmer et al., 2017) related to global product-service production. In addition a vision statement from the International Federation of Automatic Control (IFAC) Technical Committee 5.3, Enterprise Integration and Networking suggests that a common core ontology is needed to support interoperability between different models within smart sensing enterprise systems (Weichhart et al., 2016).

\section{The reference ontology approach to interoperable manufacturing knowledge systems}

The reference ontology approach takes the view that we need an ontological development method that can support information sharing across multiple domain perspectives to provide a level of semantic consistency across these perspectives. It follows the view that if any pair of domain ontologies should share information then there should

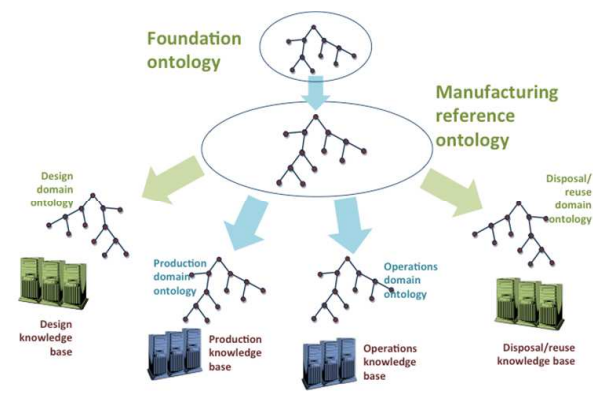

Figure 2: An overview of the specialisation approach 
be a higher-level ontology that supports these ontologies. Also, that the highest level, there will be a foundation ontology that can be exploited to support reference ontologies for other business sectors e.g. healthcare. Figure 2 provides an illustration of this basic specialisation approach.

From this basic approach the resulting reference ontology can then be readily specialised to suit the needs of any domain and/or mapped to any specific companies needs in order to both interoperably link multiple software applications and to construct a manufacturing knowledge base for the company concerned. This concept is illustrated in figure 3.
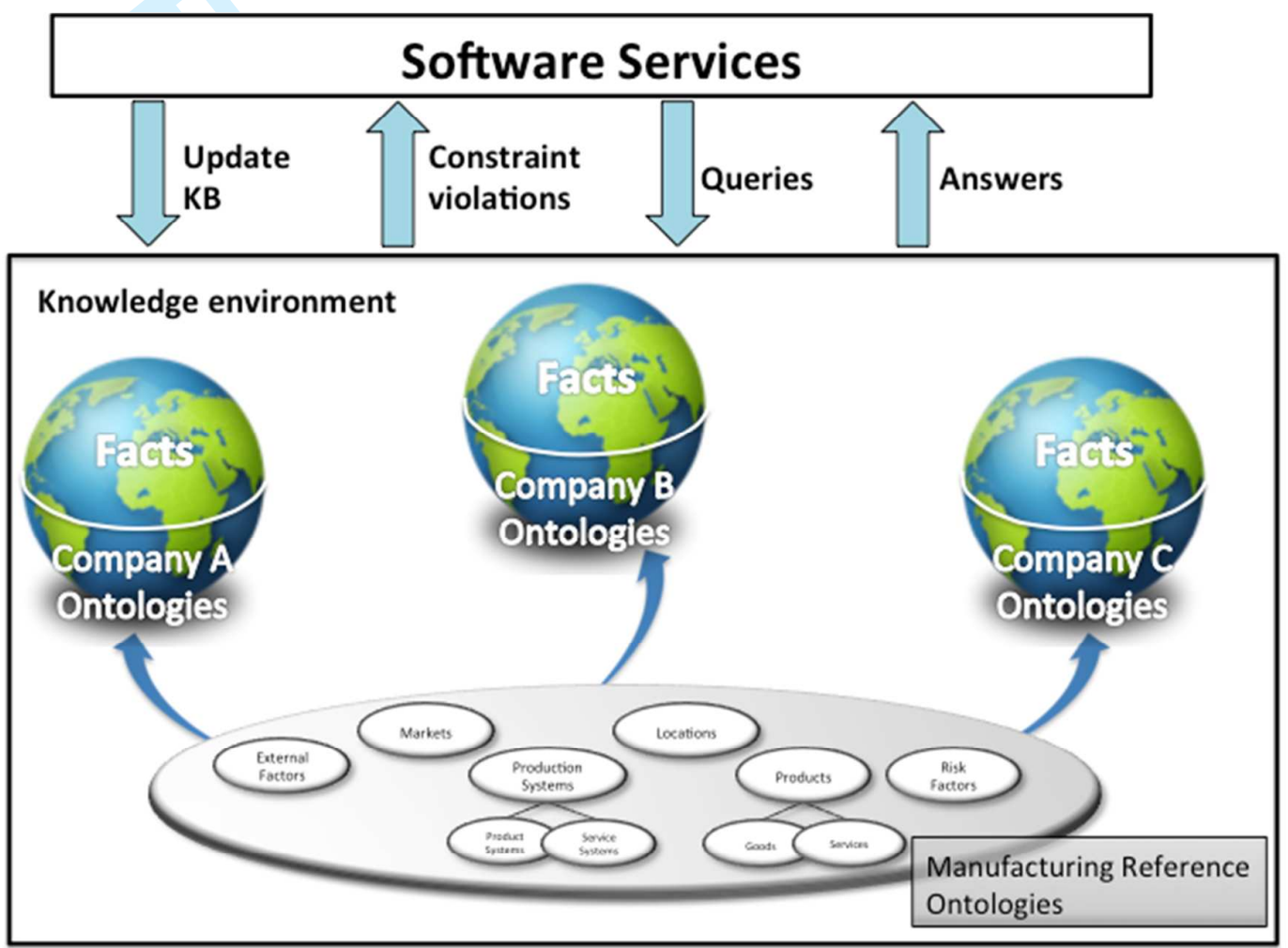

Figure 3: Exploiting a reference ontology for $\mathrm{KB}$ construction and software interoperability

In our research we have employed both a top-down approach and a bottom-up approach to identify both the core concepts that support information sharing across domains and the specific concepts that are used in a domain. In the bottom up approach specific domains are investigated and used to identify, through analyse of their interrelationships, the core concepts that apply to both. In the top down approach a view of the necessary core concepts is proposed and then specialised to suit the needs of each more specific domain.

\subsection{New understanding from a bottom-up approach}

In our research we have explored the development and exploitation of reference ontologies in a number of use cases. These are:

1. Product Design / Design for Machining (Usman et al., 2013)

2. Design for Assembly /Assembly Planning (Imran and Young, 2013) 
3. The introduction of new shop floor systems into an already integrated environment. (Hastilow and Young, 2012).

4. Product Design / Design for Manufacture of plastic injection moulded parts (Szeika, 2016)

5. Global supply network configuration to meet new business opportunities. (Young et al., 2014)

In each case the approach was based on the guidelines of Blomqvist and Ohgren (2008) and Noy and McGuiness (2000). Industrial inputs were used to develop a view of knowledge domains of interest and built an understanding of the key concepts and relationships involved. From that, and with an awareness of already existing ontologies, a reference ontology was progressively evolved and tested to support the particular domains of interest. The following theses (Usman 2012; Imran 2015; Hastilow 2013; Szejka 2016) provide the full development and evaluation of the cases listed above with the exception of item five which is discussed in section 5. A simple illustration of the first three of these is provided in figure 4, not to show any detail, but to highlight that each one is different, even though there was a general aim to build a common reference ontology. This highlights the difficultly of defining a common reference ontology as each targeted area of activity has their own perception of what is needed even though they agree on the same overall intention. A significant number iterations are likely to be needed before a truly industrially effective manufacturing reference ontology can be defined.

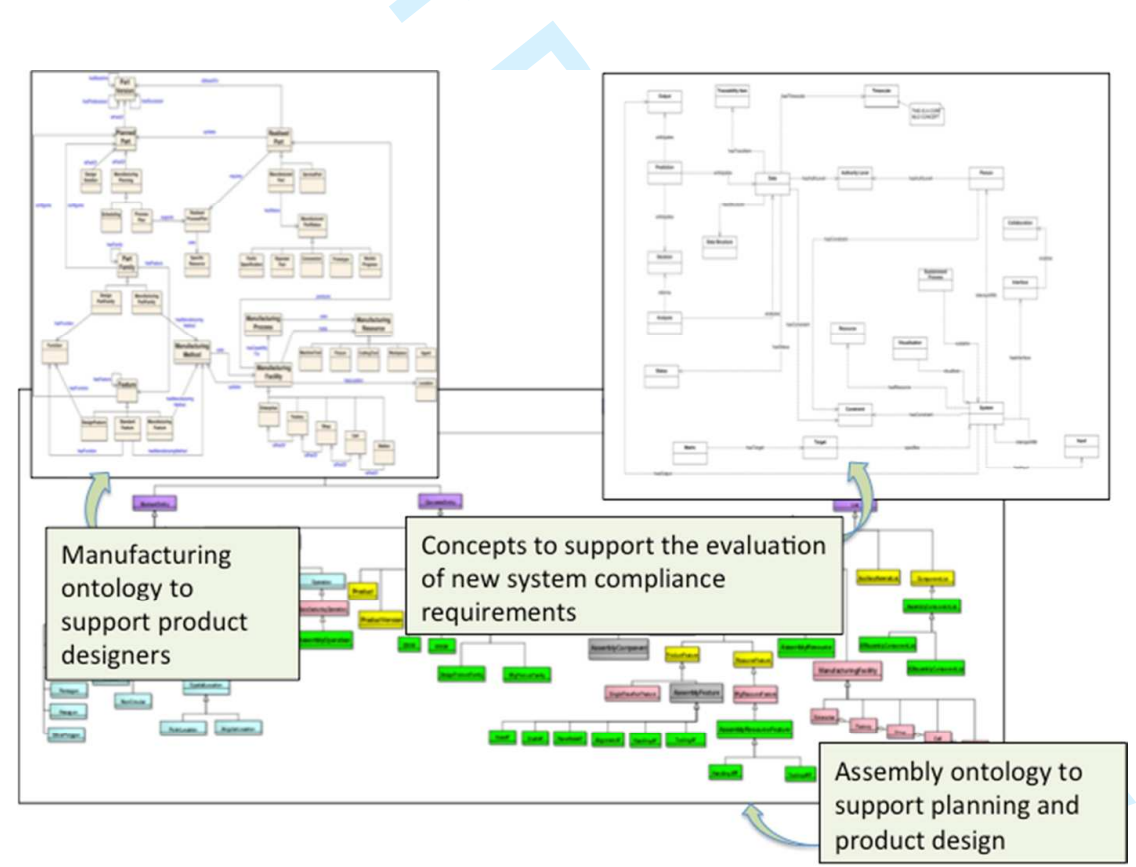

Figure 4: A graphical illustration of three reference ontologies.

These differences in results are important to understand if a common manufacturing reference ontology is ever to be achieved. The bottom up approach provides a clear set of requirements to be met by each use case. In the examples provided the only constraint that is common across the examples is the use of a common foundation ontology. Each of these research activities used the Upper Level Ontology (ULO) of Highfleet (Highfleet, 2014). The high level semantic constraints that this provides are insufficient to ensure any significant consistency across the reference ontologies. There is therefore a need to identify a more constrained or structured way of building 
reference ontologies if they are to be commonly exploitable. If a reference ontology needs to be revised rather than extended then it cannot be commonly exploitable. This emphasises the need for an iterative approach to reference ontology development as well as the need for a combined top-down and bottom-up approach as is proposed in the next section.

In addition to the work above significant progress, through the use of highly structured ontology development processes, has been made in the medical ontology development area (Arp et al, 2015). The application of this approach to manufacturing through the development of an Industry Ontology Foundry is now under extensive discussion (Morris KC and Kulvatunyou S. 2017) and is consistent with the understanding developed through the the work reported in this paper.

\subsection{Combining a bottom-up and a novel top down specialisation approach}

From the evaluation of the bottom-up approaches it is clear that a more structured approach to reference ontology development is needed if consistent and generally applicable manufacturing reference ontology is to be developed. The idea proposed follows from the recognition and supposition that all manufacturing activities can be thought of from a systems perspective and that therefore a generic systems level ontology should provide a consistent basis from which to build a manufacturing reference ontology. The approach proposed by the authors and researched in the EU FLEXINET project has the following main elements:

1. Continue to build on a specialisation approach starting from a foundation ontology and specialising down to domain levels;

2. Introduce a systems context level on which all subsequent ontology specialisation levels should be built;

3. Identify specialisation levels based on a combination of bottom-up and top down approaches i.e. identify the common requirements that can be specialised down to suit each set of domain requirements, but ensure that they remain consistent with any higher level ontologies, but especially the systems level ontology;

4. Use the resulting manufacturing reference ontology, as illustrated in figure 3 , as a means to readily construct mappings to (i) meet company specific ontological requirements, (ii) build and maintain company knowledge bases and (ii) provide a means of flexibly interfacing to a range of software services. 


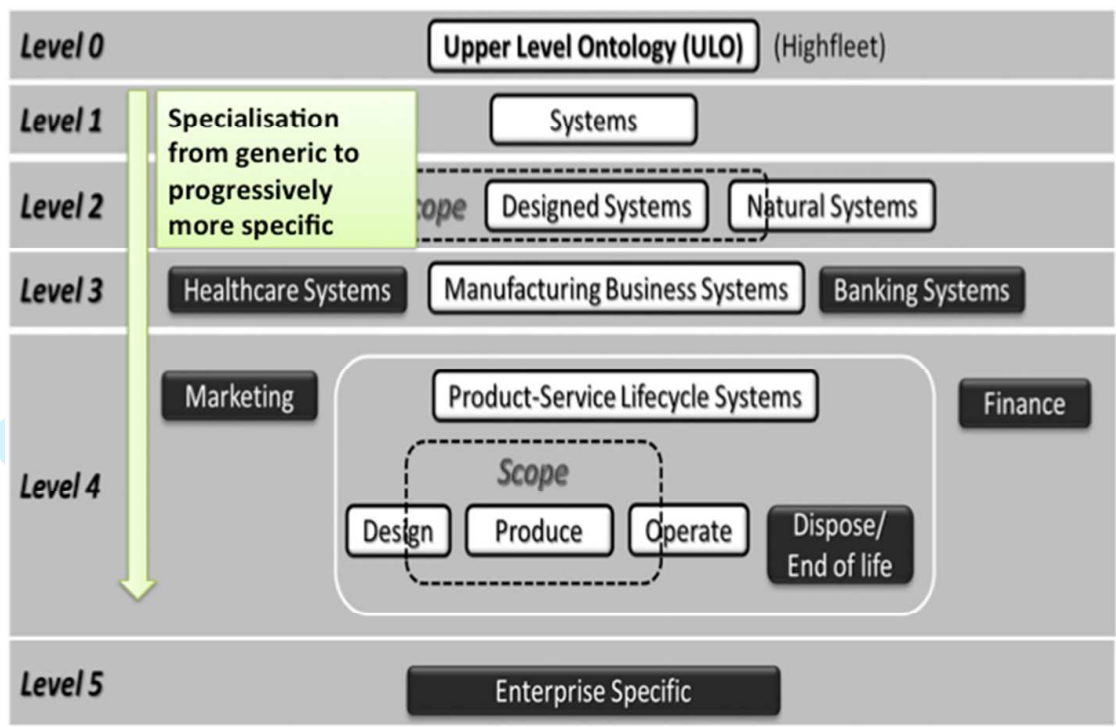

Figure 5: Specialisation from foundation to enterprise specific ontologies

The investigation of levels within the reference ontology was explained by Palmer et al (2016) and is illustrated in figure 5, with the areas in white boxes being of direct relevance to the investigations in this paper. The levels can be explained as follows:

Level 0: This is the foundation ontology level. In the research reported here Highfleet's (2014) Upper Level Ontology (ULO) has been used for this purpose;

Level 1: This provides the system's context and potentially the most important ontology level. This is explained in detail below;

Leve12: While this research is focused on manufacturing systems it is clear that many concepts could have wider applicability to any designed system. Also systems that are not developed by people, called natural systems, could also employ the level 1 concepts;

Level 3: This level contains no concepts of its own but purely provides the context for the sort of designed system for which subsequent ontology levels are to be developed. In our case this is manufacturing business systems, but it could be one of very many possibilities;

Level 4: This provides the detail level of specialisation for manufacturing business systems, with our focus being on the production aspect of the product lifecycle. While this level is developed further in section 4 , the focus of this paper is on support for high-level strategic and tactical decisions. This level will need further development and extension to support in factory operational decisions;

Level 5: This provides the ontology to support a specific enterprise and, as far as possible, will be based on mappings from level 4 , limiting new specialisations as far as possible.

\section{Note:}

1. In our presentation of the ontology we use UML class diagrams to provide an easier to comprehend visual illustration of the concepts and relations defined. In the full ontology these are defined in Highfleet's Common Logic based Knowledge Frame Language that importantly includes the logic based axioms that apply to the concepts and relations.

2. As we combine top-down and bottom-up approaches we explain in this section the top-down definition of the level 1 ontology. Levels 2,3 and 4 have resulted 
from eth bottom-up investigations in the FLEXINET project and are therefor explained in section 4 below.

The level 1 ontology has developed over time with the current concepts and relations illustrated in figure 6. One key aspect to the level 1 is the representation of Activity and System Function through the use of formalised IDEF0 concepts (PUBs 1993). The Activity concept being equivalent to an IDEF0 activity and the Roles of Input, Output, Resource and Control playing the part of IDEF0 flows. An Input represents what is brought into and is transformed or consumed by the activity to produce Outputs. A Control is a specialised Input that provides a condition required to produce the correct activity output (PUBs 1993). Resource represents the means by which an activity is performed.

Another key aspect is the definition of the two main parent classes at level 1; those of Basic and Role. A Basic concept is independent of the system or context so its definition does not depend on any other concept and an instance of a Basic always retains its identity. Role defines how Basics are used in any particular Activity. Basics occurring at level 1 are classified as Activity and Entity, with an Entity being anything of interest. Subtypes of Entity at level 1 are Information, Material and Energy. Note that Material is used to denote any material thing and not raw materials. A Basic can be comprised of Basics. This recursion can also be applied to Activity to represent subactivities or sub-system Functions. An Activity is also a subtype of Basic and provides a context for the Roles that other Basics play in its performance.

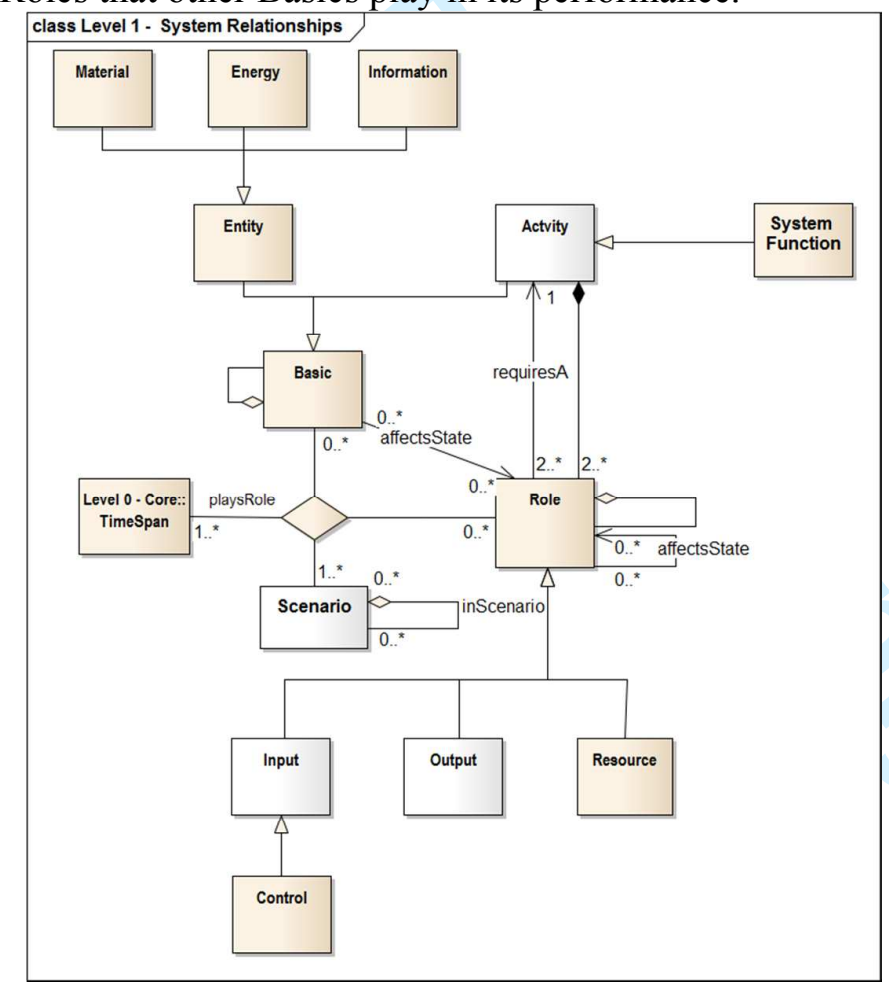

Figure 6: level 1 generic systems concepts and relationships

Role depends on Activity for its context and an instance of a Role cannot exist without such a context. Basics are used to play a Role within an Activity. Roles are also represented as being played within a Scenario, so the playsRole relation is a quaternary relation. A Basic playing a Role for certain period of time is represented using the 
TimeSpan concept and modelled using the relation "playsRole". The Scenario concept has been provided in order to represent alternative ways of meeting the same overall system requirements i.e. in production terms each scenario provides one way of providing the system output. Alternative scenarios offer the potential for companies to perform "what-if" analysis on each alternative.

Level 2 and Level 4 concepts cover an extensive range, which will continue to expand as manufacturing reference ontologies develop. How these levels have been developed within the FLEXINET project is described in the following section.

Of course, given the use of a logic based approach, there are many axioms (i.e. statements that are taken to be true) and rules that have been developed in order to constrain the use of the concepts to their intended meaning. The level 1 axioms and rules are limited in number. These are then added to as the levels of specialisation are developed and in the FLEXINET reference ontology some 55 axioms and 26 rules were developed. The level 1 axioms and rules are listed as:

1. Axiom - a role requires an activity to provide a context;

2. Axiom - an activity cannot contain a role and play the role;

3. Rule - role requires and activity (if a role requires an activity as a context then the activity contains the role)

4. Rule - activity containing a role

(if an activity contains a role then the role requires the activity as a context)

As an illustration the coding of axiom 1 is: notation for 'a role requires an activity to provide a context': :Use 1SYSCtx

$(=>$ (Role ?r) (exists (?a)

(and (Activity?a) (requiresA ?r ?a))))

:IC hard "The Role ?r requiresA Activity to provide a context."

\section{Applying the new approach in FLEXINET}

\subsection{The FLEXINET Project}

FLEXINET is focused on the early decision making processes that cut across the combination of Product-Service engineering decisions and commercial business decisions to support the dynamic evolution of global production networks. To be able to create new networks and modify old ones, flexibility is required to introduce new systems into existing networks and also to introduce new facilities or suppliers. This requires information sharing between systems across different facilities within an enterprise and between systems across multi-enterprise networks. To enhance the viability of business decisions FLEXINET draws on prior knowledge of production networks and their related global location knowledge. It provides an ideal set of business scenarios from which to research the necessary manufacturing reference ontology to support the complex knowledge sharing requirements of manufacturing businesses. These include business model development, new product development, production network configuration and risk analysis. This is illustrated in figure 7 where the "Collaboration Environments" capability is used for new product development. 
The objectives of FLEXINET from an ontological perspective were:

- $\quad$ To identify underpinning semantic concepts and their inter-relationships to support the range of software tools and business information being exploited in the project, taking into account the need for flexibility and interoperability.

- $\quad$ To create reference ontologies and compliance queries to support these tools from initial new ideas through to the development of new business models and to the development and evaluation of global production network design configurations.

The FLEXINET tools in these four areas provide decision makers with information and knowledge critical to making effective decisions drawn from the KB and analysed or updated via the applications. FLEXINET as a whole is provided as a " platform", i.e. a set of applications that can be used in combinations that can be configured to suit the specific needs of particular end users.

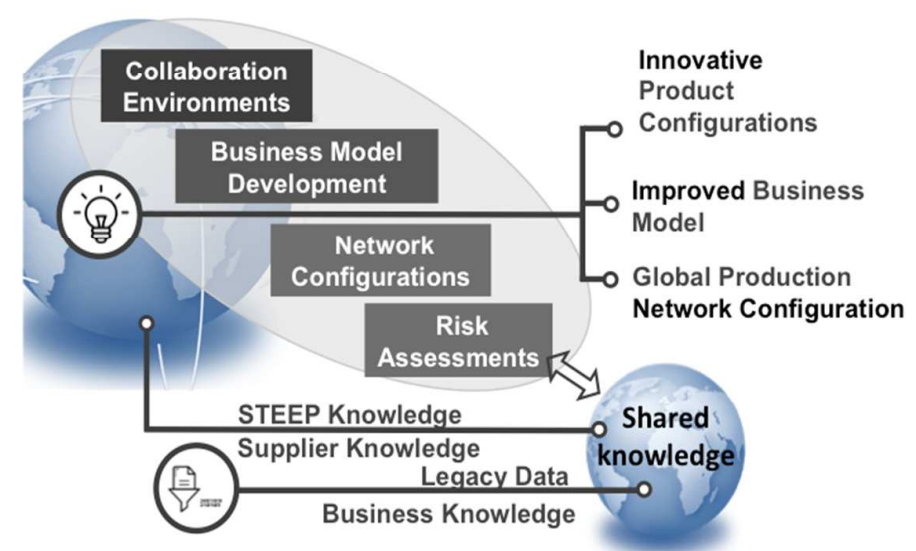

Figure 7. The FLEXINET Global Business Support Environment

\section{2 The FLEXINET Reference Ontology}

This section illustrates the comprehensive range of concepts, relationships, and constraints that have been developed and validated to demonstrate the capability of a manufacturing reference ontology. The full ontology description containing some 600 concepts, 55 axioms and 26 rules can be found in the FLEXINET project public deliverables (FLEXINET 2016).

\subsubsection{An Overview of the ontologies and inter-relationships}

The software selected to develop the reference ontology is the Highfleet Integrated Ontology Development Environment (IODE) as it utilises an expressive common logic based approach. The Common Logic based language used to implement the FLEXINET reference ontology is the Knowledge Framework Language (KFL) (Highfleet 2014). 
The FLEXINET reference ontology contains a broad range of knowledge across a number of interrelated domains as shown in figure 8. These nine domains have been defined (Project, Network, Product, Business, Risk, Scenario, Indicators, Metrics and Location) to provide the knowledge support for the applications involved the scope of FLEXINET i.e. from a bottom-up perspective.

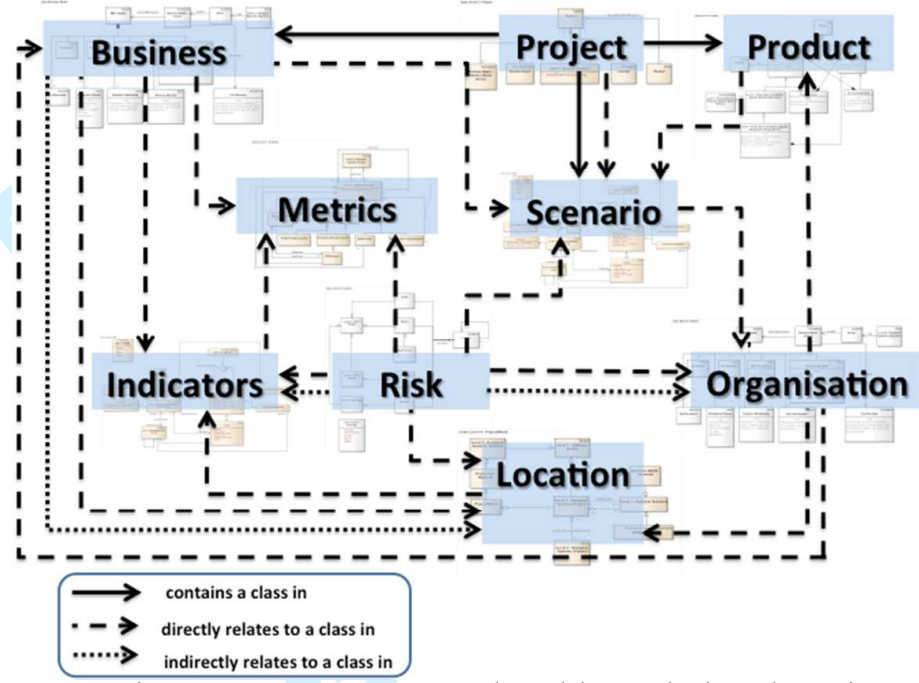

Figure 8. FLEXINET related knowledge domains

These domain ontologies use the top down levels described in section 3.2 and exploit concepts defined as specialisations of the level 1 ontology concepts. Each of the related knowledge domains are introduced in the following sub-sections, with the exception of metrics and indicators, as they do not add to the general argument of the approach.

To support interoperability across the applications supported by the ontology multiple relationships exist between the domains of the reference ontology. Three types of relationship exist, as illustrated by the arrows shown in Figure 8:

- $\quad$ Direct Relationships

- Containment Relationships

- Indirect Relationships

Direct relationships are defined when a relation exists between properties which are situated in two or more domains (a cross-domain relation). Direct relationships can take the form of binary, ternary or quaternary relations. Examples of binary direct relationships are: "locationHasExternalFactor" which links the Location and Indicator domains; and "hasIndicatorValue" which specifies "Indicator" and "Metric" as its arguments and forms a connection between the corresponding domains.

A containment relation occurs when a property in a domain is a container for a property in a separate domain. It is specialism of a binary direct relationship. For example, the "Project" property from the Project domain contains a "Business Model Canvas" from the Business Model domain. The top level containment relation in FLEXINET is "basicContainsBasic".

Indirect relationships require two or more relations to link separate domain areas within the reference ontology. They are formed from a chain of arguments which connects the relations, i.e. Argument $\mathrm{A}$ which is a member of domain $\mathrm{X}$ is associated with argument $\mathrm{B}$ through relation 1. Argument $\mathrm{B}$ is associated with argument $\mathrm{C}$ 
(contained in domain Y) through relation 2. An example of an indirect relation is the connection between the Location domain and the Business domain. The two connecting relations which connect the domains are "facilityLocatedAt" and "playsRole". An instance of a Facility (a general Level 2 property) is associated with a Location through the "facilityLocatedAt" relation. Within the Business Canvas model system the Facility instance plays the role of a KeyPartner (relation "playsRole", domain "Business").

Examples of level 2 system concepts are illustrated in figure 9 and role concepts that are played by Basics are illustrated in figure 10. Of particular importance for FLEXINET high-level decisions are the system concepts of Organisation and Facility and the Roles of Supplier, Producer and Customer.

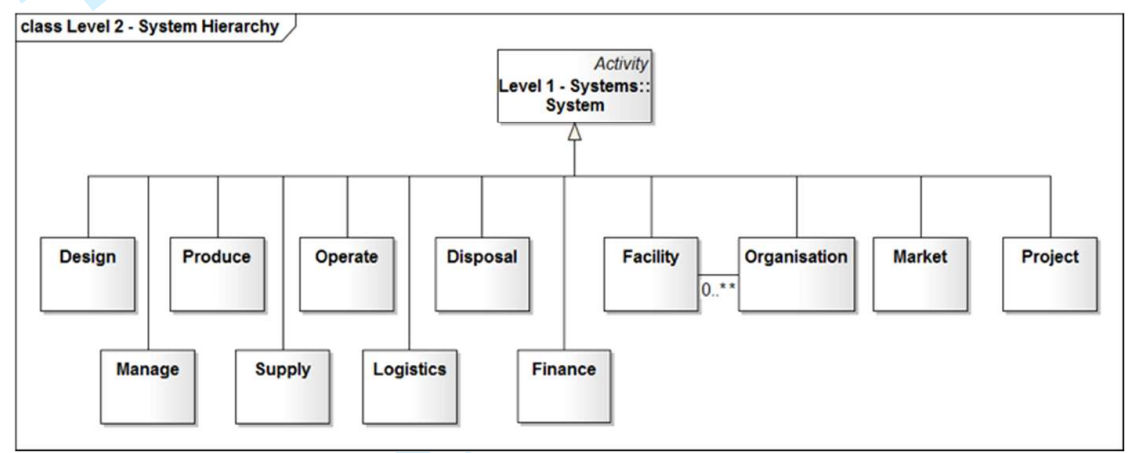

Figure 9. Examples of level 2 System concepts

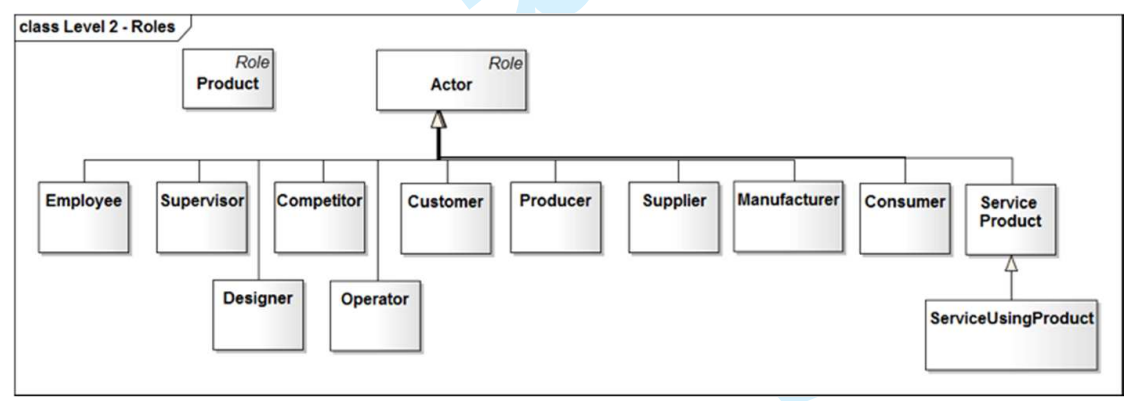

Figure 10. Examples of level 2 Role concepts

\subsubsection{Organisation}

The Organisation and Facility concepts are illustrated in figure 9 as specialisations of the System concept. Organisation is synonymous with an enterprise which Facility represents a system within an Organisation which has a specific location e.g. a factory or a service centre. A Factory would then be further developed into its operational capability, although this development has been outside the scope of FLEXINET.

\subsubsection{Scenario}

As mentioned in section 3.2 alternative scenarios offer the potential for companies to perform "what-if" analysis on each alternative. So scenarios can be developed for products or business models or risk or, of particular importance in manufacturing, of production networks. The Network Level 2 ontology, illustrated in figure 11, can then be specialised at level 4 into a production network or global production network. 


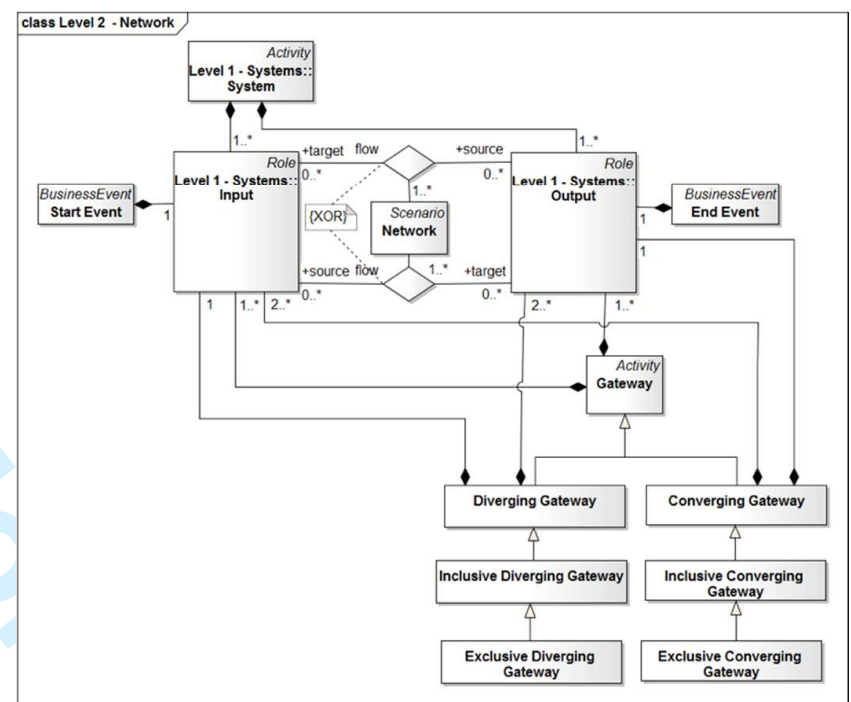

\subsubsection{Project}

Figure 11. The level 2 Network ontology

Project is defined as a planned set of interrelated tasks to be executed within time and cost limitations. The elements of a project of importance in FLEXINET were related to Business models, represented as a Business Model Canvas, Decision Event, Scenario, Concept (here with the meaning of a product concept) and Product. These are illustrated in figure 12.

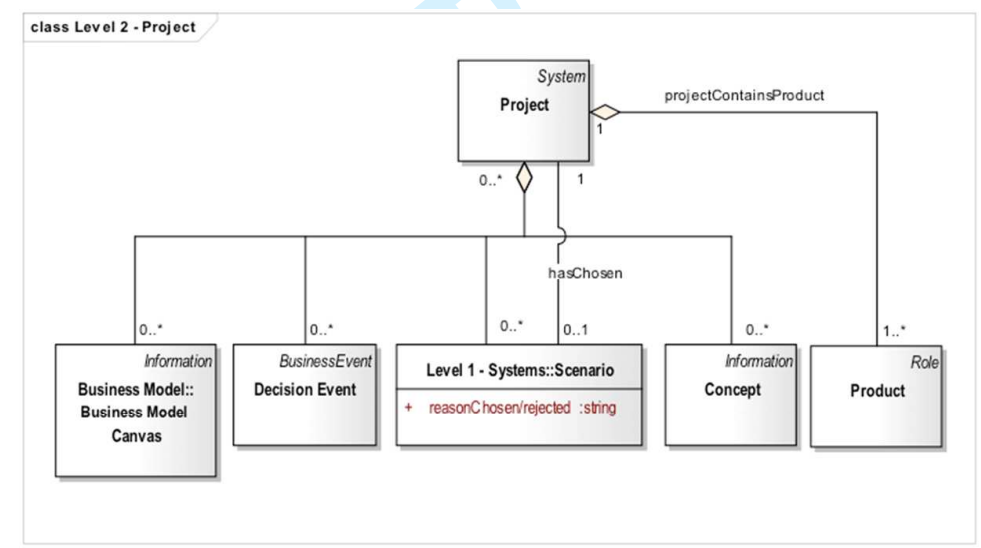

Figure 12. The level 2 Project properties

\subsubsection{Product}

Product is clearly a domain that has a huge range of potential concepts within its scope. In FLEXINET the requirement has been to distinguish between physical products and service products. This has been achieved as illustrated in figure 13, where a Physical Product" is 'a material artefact'. A "Service Product" refers to 'an offering'. A "Service Using a Product" is 'an offering that employs a physical product' e.g. power by the hour. A "Product Service" is 'a physical product that also provides a service offering that delivers value in use' (Annamalai et al., 2011). A "Manufactured Product" is a product that exploits/consumes raw materials. A Manufactured Product Service is a specialisation of Manufactured Product that also provides a service offering. 


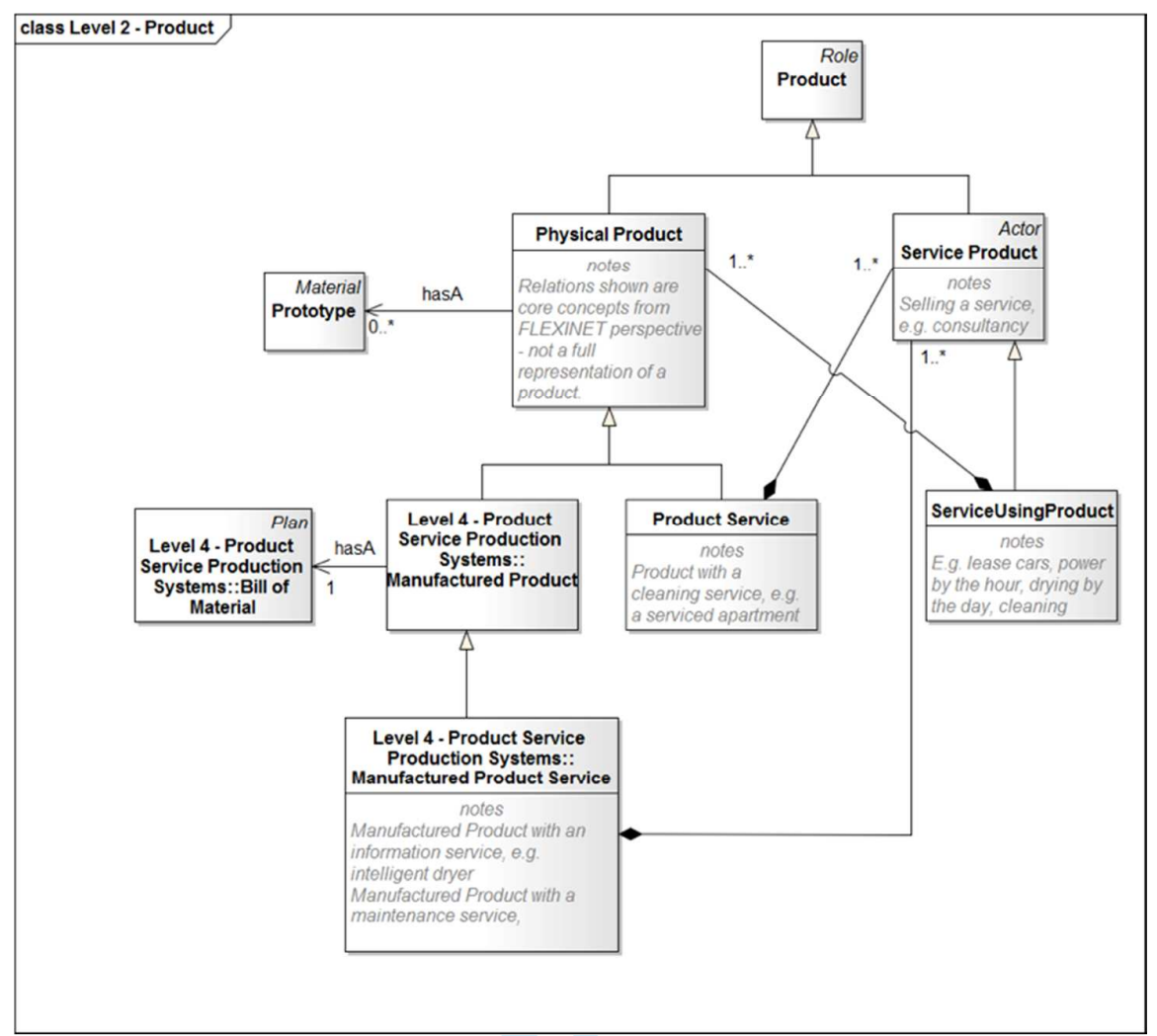

Figure 13. The level 2 and level 4 product properties

\subsubsection{Business}

The Business Model properties linking business objectives to the elements of a Business Model Canvas is represented in figure 14. In addition the Business model includes support for the use Balanced Score Card techniques and as such has links defined from balanced scorecard views to indicators as illustrated in figure 15 .

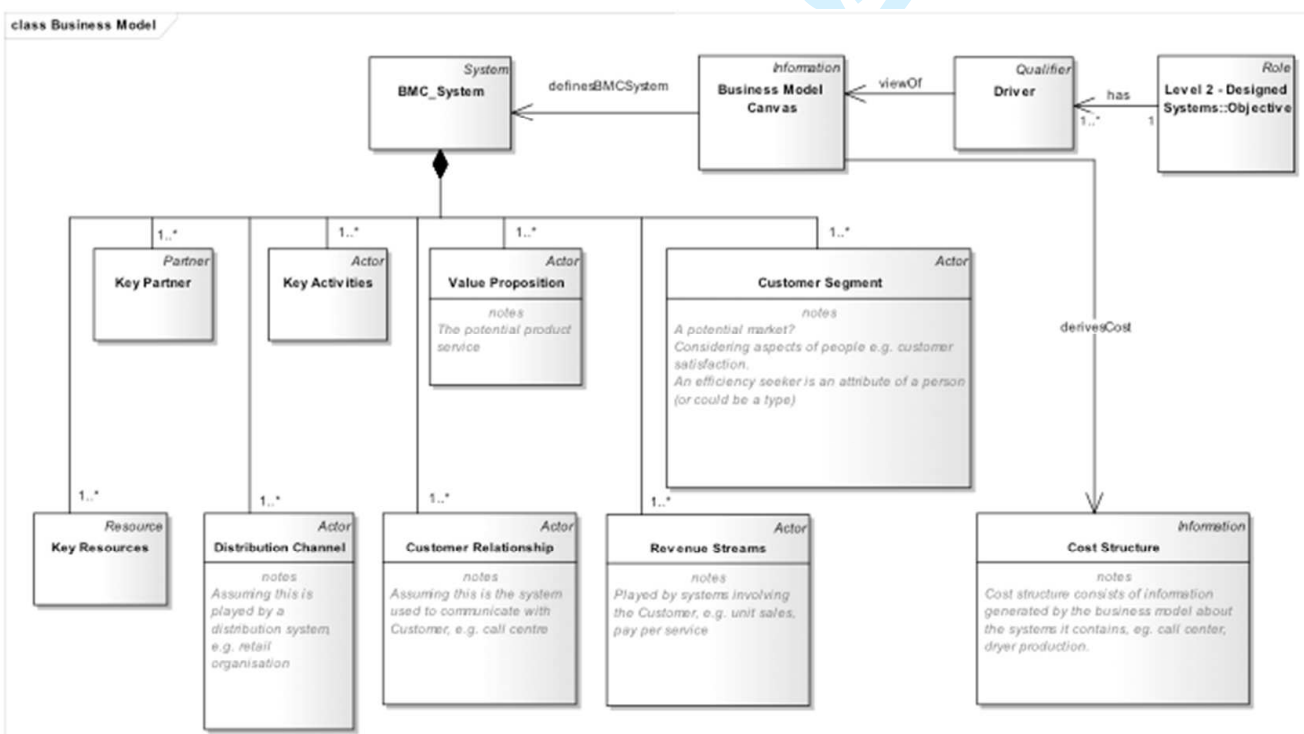

Figure 14. The level 2 Business Model properties 


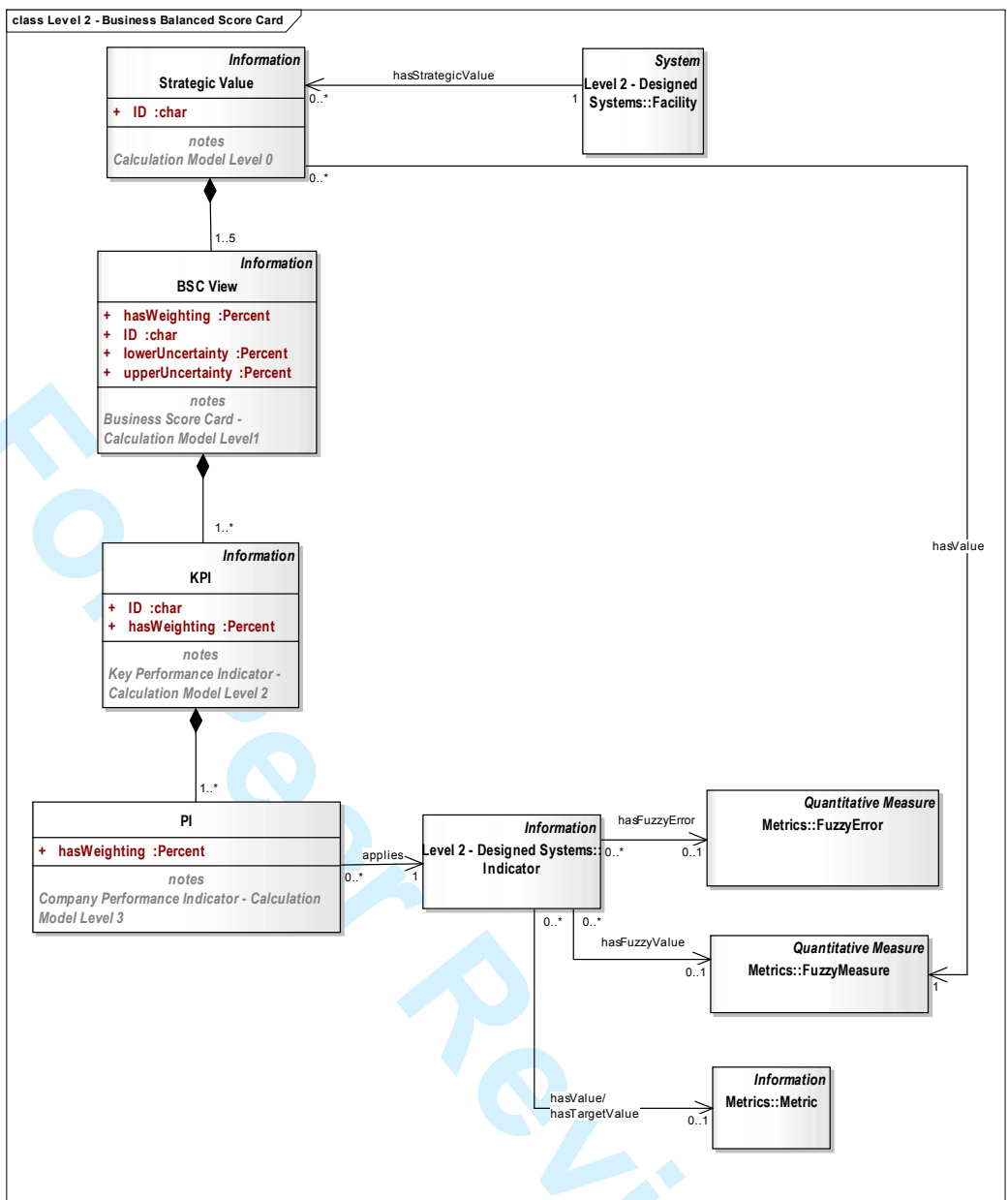

Figure 15. Balanced Score Card linked to indicators and metrics 


\subsubsection{Location}

Location is an important concept for globally based decision making. The appropriate definitions for Location are dependent on use and can be difficult to define precisely as location boundaries are often determined by human demarcation (Smith \& Varzi, 2000). In FLEXINET Location supports decisions related to global production networks, business rules and risk assessment. The ontology for location used in FLEXINET is shown in figure 17. 


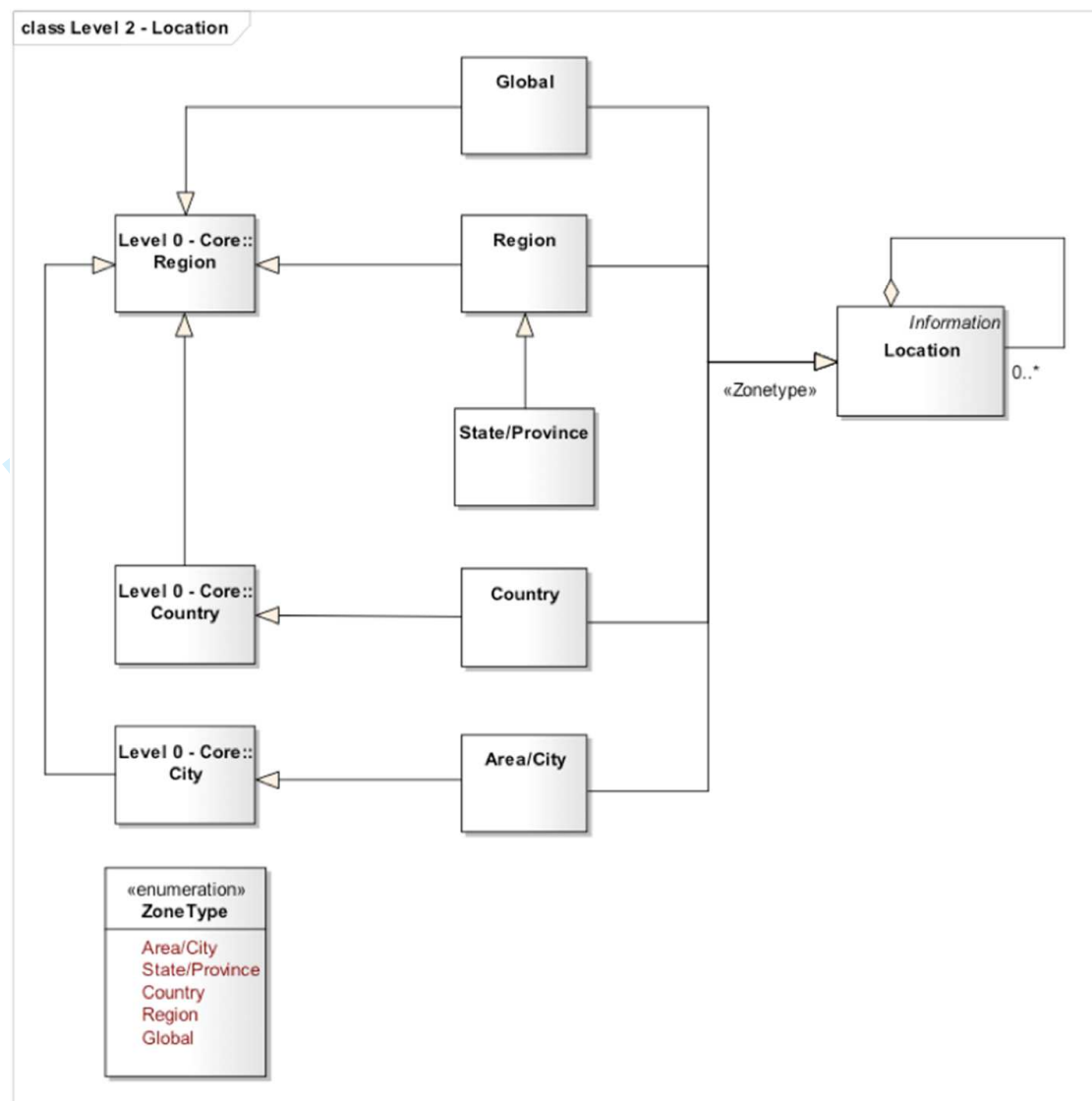

Figure 17. Level 2 Location properties.

\subsection{Exploiting the FLEXINET Reference Ontology}

The FLEXINET project has constructed and interacted with four knowledge bases in order to test the capability of the reference ontology. These KBs were one for each of our manufacturing company partners in pumps manufacture, white goods and in food \& drink plus a fictitious bike company that could be used for generic dissemination. Figure 18 illustrates 6 of the main application software tools set in the context of the business, product and production development timeline. The applications being idea and concept management, business model canvas development, business model evaluation, product-service configuration, product network configuration and risk analysis. In addition to these applications there are also some pre-configuration applications which allow the company to pull in legacy data, existing supplier knowledge, business rules and external global Social, Technological, Economic, Environmental and Political (STEEP) information. 
These applications all interact via the knowledge base for information inputs and outputs, all based on the underlying reference ontology. Examples of key interactions are (i) between the generation of a new product concept in the Idea Manager application and the use of this as a value proposition in the Business Model Canvas application and (ii) in the Global Product Network application which checks the Location of any potential Facility against the company's business rules and the external STEEP data for that Location. Figure 19 illustrates a user interface with a global production network configuration application.

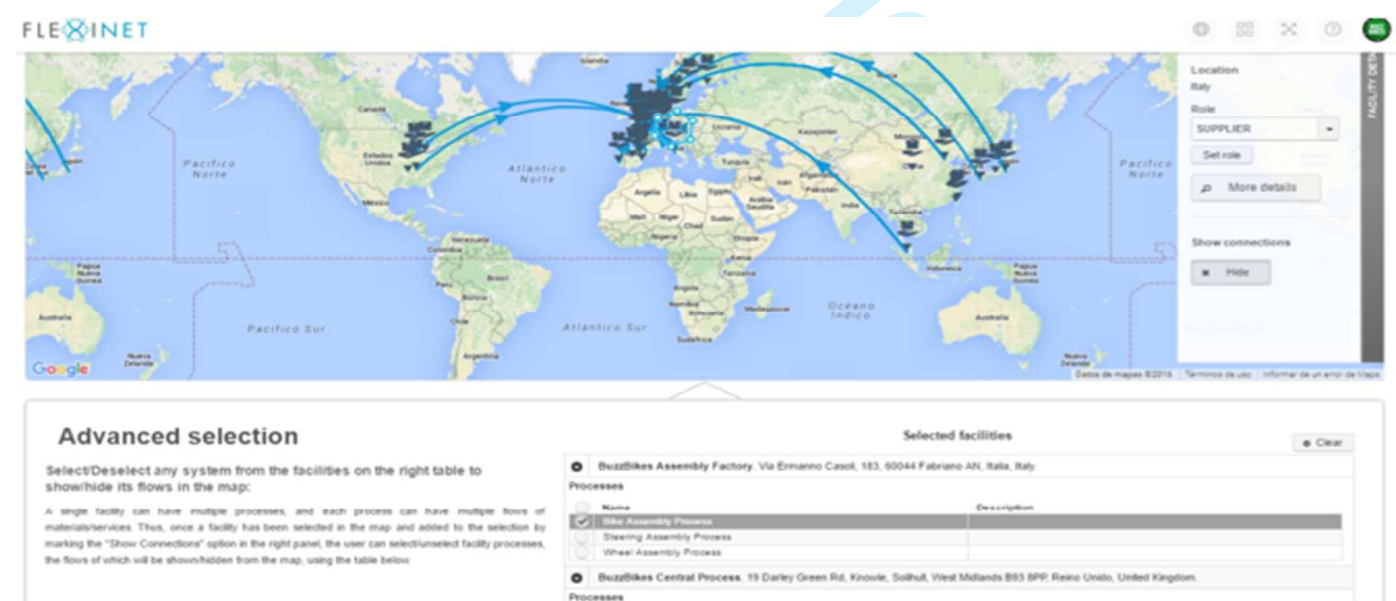

Figure 19. User's view of global facility location along with defined flows in the network.

The ontology supports reasoning in order to offer appropriate information to the applications by means of applying queries to a populated knowledge base. Queries are presented which guide user decisions. In the query shown in figure 20 an assessment is being made as to whether a facility is suitable to be a Key Partner within a Business Canvas Model. The end user "DrinksCo" has specified business policy requirements within the knowledge base using the "specifiesBusinessPolicy" and 
"hasThresholdValueForIndicator" relations. For example, it can be seen that "DrinksCo" has stipulated that GDP must be greater than or equal to \$2000. This query is requesting the business policies specified by "DrinksCo" and comparing these values with the external factors of the locations of facilities within the knowledge base.

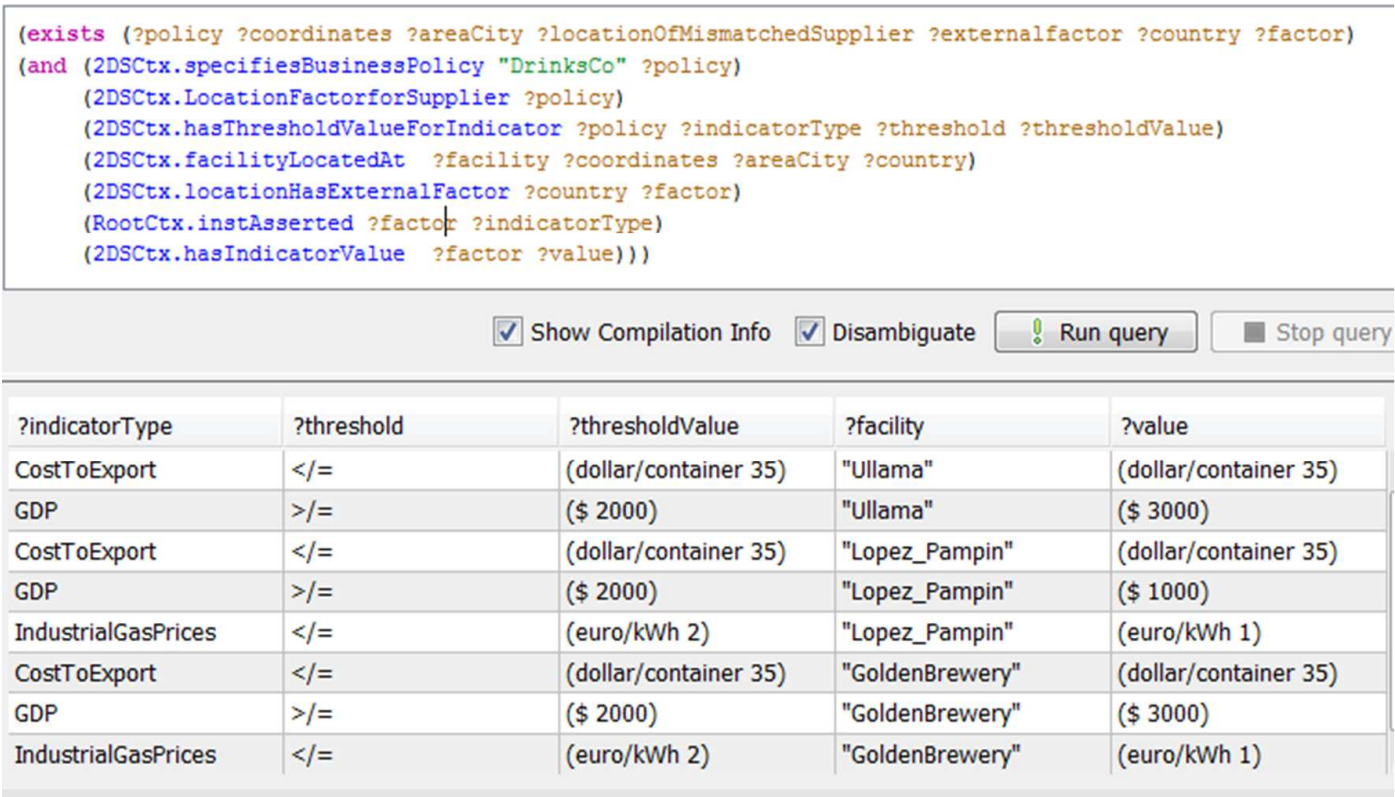

Figure 20 Query to check for suitable Key Partners

The user is able to use the results returned by this query to select a suitable facility to be a key partner within a Business Canvas Model which will create an indirect relationship between the Location domain and the Business Canvas Model domain.

\section{Concluding discussion}

Whilst there are many projects which have capture sets of manufacturing concepts what makes this work distinctive is that it captures the logical relationships between these concepts as well as constraints on their use, so that the knowledge of their interactions can be effectively captured and applied in complex business development, product development and production network configuration activities. Not only does it define a formal manufacturing reference ontology but it does this using a flexible and extensible approach that is fundamental to future development as businesses evolve.

The FLEXINET reference ontology comprises approximately 450 properties and 650 relations. As FLEXINET is focused on the strategic and tactical levels of business decision making most of the concepts and relations within the reference ontology occur at a high generic level. The previous domain descriptions indicate Level 2 contains the majority of constructs (330 properties and 435 relations). Level 4 contains 110 properties and 190 relations specialised to the manufacturing business systems domain.

The FLEXINET ontology is focused on strategic and tactical decision support for new business opportunities. It has been used successfully by our industrial partners and with our software partners as a basis for knowledge capture, use and sharing. Importantly this has been successful across the three industrial sectors involved in the project. 
Perhaps the most important aspect of the FLEXINET ontology is the level 1 ontology as this provides an important bridge from foundation ontologies to clarify the meaning of the concepts at level 2 and level 4. This helps to avoid the problems of developing multiple incompatible reference ontologies.

Manufacturing reference ontologies contribute to supporting multi-faceted decision-making by providing a knowledge framework, including key cross-domain relationships. This means that the implications of decisions from one viewpoint can be applied to other related viewpoints. Hence the user has the most appropriate information to make intelligent multi-perspective decisions, reacting rapidly and reducing cost through the use of high quality information. The inter-relationships within the reference ontology enable:

- $\quad$ Flexible approaches to information sharing across systems;

- Decisions taken in one domain to be understood within another domain;

- The ability to readily configure "common" business knowledge bases;

- Enable a migration path towards interoperable standards across a more broadly based manufacturing scope;

The Inter-relations between the different focused knowledge domain ontologies, as demonstrated in FLEXINET and illustrated in figure 8, support interoperability across multiple applications. However, this raises issues in the maintenance and development of a reference ontology, as the interrelationships between these domain ontologies need to be managed with care. Nonetheless it is clear that it would be of great benefit for future ontology development if a pre-defined set of relatively narrow ontologies could be available for use in building the reference ontology. This would effectively provide a library of ontologies or potential knowledge libraries that could be used and reused. This would both minimise the cost and time in building the reference ontology and also improve the ability of multiple reference ontologies to interoperate.

The FLEXINET ontology requires extension to broaden its scope of application to in-factory decision support and to support operational level supply networks to be more fully be aligned with the aims of Indusrie 4.0. The upper levels of the ontology could also be exploited for other domains outside of manufacturing.

\section{Acknowledgements}

We wish to acknowledge the FLEXINET consortium and especially the financial support from the European Union Seventh Framework Programme FP7-2013-NMP-ICT-FOF (RTD) under grant agreement no 688627.

We also wish to acknowledge the support of the EPSRC in the early research understanding presented in this paper who funded the Interoperable Manufacturing Knowledge Systems (IMKS) under project 253 of the Loughborough University Innovative Manufacturing and Construction Research Centre (IMCRC).

We also wish to acknowledge the Brazilian Science without Borders programme who supported inputs through the "Intelligent Knowledge Libraries: exploiting new ICT technologies for improved Manufacturing Intelligence" project. 


\section{References}

Annamalai, G., Hussain, R., Cakkol, M., Roy, R., Evans, S., \& Tiwari, A., 2011. An ontology for Product-Service Systems. Decision Engineering Report Series, R. Roy and Y Xu (Eds.). Cranfield University.

Arp R., Smith B., Spear A. (2015) "Building ontologies with basic formal ontology” The MIT press. ISBN 9780262527811.

Blomqvist, E. and A. Öhgren (2008). "Constructing an enterprise ontology for an automotive supplier." Engineering Applications of Artificial Intelligence 21(3): 386-397.

Borgo, S., and Leitão, P. 2007, Foundations for a core ontology of manufacturing. Integrated Series in Information Systems, Volume 14, pp 751-775.

Borsato, M., 2014. Bridging the gap between product lifecycle management and sustainability in manufacturing through ontology building. Computers in Industry, 65, pp. 258-269

Bruno G., Korf R., Lentes J., Zimmerman N., (2016). "Efficient management of product lifecycle information through a semantic platform". Int. J. Product Lifecycle Management, Vol. 9, No. 1.

Chen, D., Knothe, T., \& Doumeing, G., 2009, POP* Meta-Model For Enterprise Model Interoperability. Proceedings of the 13th IFAC Symposium on Information Control Problems in Manufacturing. Moscow, Russia, June 3-5, pp. 176-180.

Chungoora, N., \& Young, R.I.M. (2011). The configuration of design and manufacture knowledge models from a heavyweight ontological foundation. International Journal of Production Research, 49(15), pp. 4701-4725.

Chungoora, N., Gunendran, G.A., Young, R.I.M., Usman, Z., Anjum, N.A., Palmer, C., Harding, J.A., Case, K., and Cutting-Decelle, A.F., 2012. Extending product lifecycle management for manufacturing knowledge sharing. Proceedings of the Institution of Mechanical Engineers Part B - Journal of Engineering Manufacture, 226 (A12), pp. 2047-2063.

Chungoora, N., Cutting-Decelle, A-F., Young, R.I.M., Gunendran, G., Usman, Z., Harding, J.A., Case, K., 2013. Towards the ontology-based consolidation of production-centric standards, International Journal of Production Research, vol. 51 no. 2 , pp. 327-345.

FLEXINET (2016) "product service ontology report". http://www.flexinetfof.eu/Documents/FLEXINET\%20D3.5\%20Product-Service-Production\%20Ontologies.pdf

Gruninger, M. and J. Lee (2002). "Introduction: Ontology Applications and Design." Communications of the ACM $45(2)$.

Highfleet (2014) Highfleet Ontology Library Reference, Baltimore, MA: HIGHFLEET Inc

Hastilow N., Young R. (2012). "Understanding 'Manufacturing Intelligence' - a precursor to interoperable manufacturing systems" in Enterprise Interoperability VII: Proceedings of the I-ESA Conferences 8, pub Wiley 2012.

Hastilow N 2013 Manufacturing systems interoperability in dynamic change environments $\mathrm{PhD}$ thesis, Loughborough Univeristy, Loughborough, UK. https://dspace.lboro.ac.uk/dspace-jspui/handle/2134/13174

Huber A. (2014) presentation by Siemens CEO, World Manufacturing Forum, Milan, July 2014. http://www.ims.org/2014/07/world-manufacturing-forum-2014/ [Accessed April 2016].

Imran M and Young R (2013) "The acclication of common logic based formal ontologies to assembly knowledge sharing” Journal of Intelligent Manufacturing. Vol. 26(1), pp 139-158. Jan 2013

Imran M 2015. "Towards an Assembly Reference Ontology for Assembly Knowledge Sharing". PhD thesis, Loughborough Univeristy, Loughborough, UK. https://dspace.lboro.ac.uk/dspace-jspui/handle/2134/13995

ISO/IEC-24707. (2007). Information technology - Common Logic (CL): a framework for a family of logic based. Retrieved 08 14, 2011, from Common Logic Standard: http://standards.iso.org/ittf/licence.html

Kagermann H., Wahlster W., Helbig J. (2013) "Recommendations for implementing the strategic initiative INDUSTRIE 4.0" Final report of the Industrie 4.0 working group. Pub April 2013. Office of the IndustryScience Research Alliance, beim Stifterverband für die Deutsche Wissenschaft, Ulrike Findeklee, M.A. ulrike.findeklee@stifterverband.de or contact kontakt@platform-i40.de

D Leal, A Feeney. An Architecture for Industrial Data Standards, Report to ISO TC184 SC4 15 June 2010

Mascardi, V., Locoro, A., Rosso, P. (2010). Automatic Ontology Matching via Upper Ontologies: A Systematic Evaluation. IEEE Transactions on Knowledge and Data Engineering, May 2010, Vol.22(5), pp.609-623.

Morris KC., Kulvatunyou S. (2017) http://blog.mesa.org/2017/03/working-towards-industrial-ontology.html

Noy, N. F. and D. L. McGuinness (2000). Ontology Development 101: A Guide to Creating Your First Ontology. D. L. McGuinness.

Oh, S., Yeom, H.Y. and Ahn, J. (2011). Cohesion and coupling metrics for ontology modules. Information Technology and Management, 12(2), pp.81-96.

Palmer, C., Urwin, E.N., Pinazo-Sánchez, J-M, Cid, F.S., Rodríguez, E.P., Pajkovska-Goceva, S. and Young, R.I.M. (2016), 'Reference Ontologies to Support the Development of Global Production Network Systems', Computers In Industry, Vol. 77, pp. 48-60.

Palmer, C., Urwin, E.N, Marilungo E. and Young, R.I.M., 2017, "Reference ontology approach to support global product-service production", International Journal of Product Lifecycle Management.??

Pattenden, S., Young, R., and Zelm, M. Standardisation Task Force Report to Future Internet Enterprise Systems (2012)

Ray, S. R., \& Jones, A. T., 2006, Manufacturing interoperability. Journal of Intelligent Manufacturing, 17(6), 681688. 
Shvaiko P. \& Euzenat J., 2013. Ontology Matching: Stae of the art and future challenges. IEEE Transactions on knowledge and data engineering. Vol 25. Issue 1. pp 158-176

Sureephong, P., N. Chakpitak, Y. Ouzrout and A. Bouras. 2008. "An Ontology-based Knowledge Management System for Industry Clusters." In International Conference on Advanced Design and Manufacture (ICADAM 2008). Sanya: China.

Szejka A L (2016) "Contribution to interoperable product design and manufacturing information: application to plastic injection products manufacturing" Doctoral thesis of the Pontifical Catholoic University of Parana, Brazil and the University of Lorraine, France.

Uschold, M. King, M., Moralee, S., \& Zorgios, Y., 1998). The enterprise ontology, The Knowledge Engineering Review, 13 (1), pp. 31-89.

Usman, Z., Young, R.I.M., Chungoora, N., Case, K., Palmer, C. and Harding J.A.,(2013), 'Towards a formal manufacturing reference ontology', International Journal of Production Research, Vol. 51, Iss. 22, pp. 65536572 .

Usman Z. 2012. "A Manufacturing Core Concepts Ontology to Support Knowledge Sharing" PhD thesis, Loughborough Univeristy, Loughborough, UK. https://dspace.lboro.ac.uk/dspace-jspui/handle/2134/9857

Weichhart, G., Molina, A., Chen, D., Whitman, L.E. and Vernadat, F., 2016. 'Challenges and current developments for sensing, smart and sustainable enterprise systems', Computers in Industry, vol 79, pp.34-46.

West M., Fowler J. (2001) “The IIDEAS architecture and integration methodology for integrating enterprises" PDT Days 2001

Ye, Y., Yang, D., Jiang, Z., \& Tong, L. ,2008, Ontology-based semantic models for supply chain management. The International Journal of Advanced Manufacturing Technology, 37(11), 1250-1260.

Young, R. I. M., Gunendran, A. G., Cutting-Decelle, A. F., \& Gruninger, M. , 2007. Manufacturing knowledge sharing in PLM: a progression towards the use of heavy weight ontologies. International Journal of Production Research, 45(7), 1505-1519.

Young, R., Pooplewell K., Jaekel F-W., Otto B., Ghullar G., (2014) "Intelligent Systems Configuration Services for Flexible Dynamic Global Production Networks" Workshop on Interoperability for Enterprise Systems and Applications. I-ESA 2014. 